\title{
Analysis of Petroleum Geological Exploration and Reservoir Evaluation Methods
}

\author{
Xin Guan \\ Liaohe Oilfield Exploration and Development Research Institute, Panjin, Liaoning, 124000. China
}

\begin{abstract}
As one of the important natural resources, oil resources play an irreplaceable role in China's social and economic development. At present, the social demand for oil is increasing gradually, and China's oil production is in the forefront of the world, which is both an opportunity and a challenge for the development of the oil industry. The research on petroleum geological exploration and storage in China is relatively lacking. As a non-renewable resource, excessive exploitation of oil will lead to the shortage of natural resources in China, which is not only extremely unfavorable to the development of the oil industry, but also leads to the collapse of China's social economy. Therefore, the relevant staff must do a good job in the corresponding reservoir work, conduct in-depth research on the exploration technology, and fully implement the reservoir evaluation scheme system, so as to improve the overall comprehensive level of China's petroleum geological exploration, carry out protective development on the utilization of petroleum resources on the basis of meeting the needs of China's social development, and improve the utilization rate of petroleum resources.
\end{abstract}

Keywords: Oil, Geological exploration, Reservoir evaluation method, Explore.

\section{Introduction}

With the continuous development of China's social economy, China's comprehensive national strength has been greatly improved. As one of the important strategic resources, oil resources have an excellent role in promoting China's comprehensive strength. However, the national dependence on oil has reached more than $70 \%$. At present, most of China's oil fields are in the middle and late stage of exploration, which will not only seriously affect the stable development of China's society, but also hinder the improvement of China's comprehensive strength, resulting in the limitation of China's survival and development. Therefore, when carrying out daily exploration, relevant staff must do a good job in geological exploration technology, conduct in-depth research on its technology, and fully implement the storage evaluation system, so as to improve the quality and efficiency of oil exploitation, improve the oil utilization rate, alleviate the current situation that China's oil supply exceeds demand, and provide power for the stable and long-term development of China's economy, Comprehensively improve China's comprehensive strength.

\section{Summary of petroleum geological exploration}

Petroleum geological exploration technology is mainly to ensure that petroleum enterprises can obtain high-quality petroleum resources in the mining process and improve the mining safety and reliability of petroleum enterprises. Therefore, petroleum geological exploration technology plays an irreplaceable role in the development of petroleum industry, and its quality and efficiency will directly determine the output of Chinese petroleum enterprises. Although China has abundant oil reserves, compared with other developed countries, China has less exploitable oil reserves and low production. Most of the oil resources are still in the undeveloped stage, mainly because most of the oil is located in several kilometers underground, and the surface environment will be damaged during the exploitation of stone oil, It is easy to cause collapse of geological structure. In the process of oil exploitation, relevant staff need to do a good job in corresponding exploitation, and conduct in-depth analysis on the specific structure, reservoir conditions and surface environment of the oil area, so as to formulate a scientific and reasonable exploitation scheme, so as to avoid potential safety problems in the exploitation process and affect the overall quality and efficiency of oil exploitation. China's petroleum geological exploration is mainly divided into sedimentary structure exploration, 
permeability rhythm exploration, horizontal and vertical permeability and particle size rhythm. Among them, sedimentary structure exploration is mainly to explore the underground bedding. In the process of oil exploration, the underground bedding is different, and its permeability will also be different. For example, horizontal bedding, massive bedding, etc., both of which have different penetration directions. The staff can judge the specific situation of the oil resource stratum by exploring the sedimentary structure, so as to judge the oil resource area. The horizontal permeability and vertical permeability are mainly used to judge the formation permeability during reservoir water injection. Generally, the horizontal permeability and pure plant permeability are located in a high position, so the water washing range is large and the overall fluid permeability is ideal. The particle size rhythm is mainly based on the law of debris particle change in sand dust to explore the oil underground. The physical shape of sand layer will be different with different particle size rhythm. The staff can clearly identify the specific conditions of the formation by using the particle size rhythm exploration technology. Finally, the permeability rhythm exploration contains more contents. Such as positive rhythm transformation, anti rhythm transformation and consistent rhythm transformation. In the process of petroleum geological exploration, the rhythmic exploration of permeability can distinguish the oil permeability of different rhythms, so as to master the actual situation of oil formation, formulate corresponding production measures according to the actual situation, and do a good job in safety while ensuring the quality and efficiency of oil production.

\section{Current situation of petroleum exploration in China}

\subsection{Higher degree of practicality}

With the decrease of China's oil exploitation, the available oil resources are gradually shrinking. Therefore, the relevant staff need to focus on the practicality of oil geological exploration technology research, improve the practicality of oil geological exploration work in an allround way, and re-integrate and adjust oil exploitation projects, so that they can adapt to the development of the times and meet the needs of the public. Relevant staff can change the focus of traditional petroleum geological exploration, change the research object, and conduct petroleum geological exploration technology research based on medium-term and short-term needs, so as to ensure the long-term development of petroleum exploration technology and solve the situation that China's oil resources are in short supply.

\subsection{Gradually introduce innovative ideas}

With the changing structure of China's national economy, China's oil industry is also facing many challenges, especially the shortage of oil resources. The shortage of oil resources will not only affect the harmonious development of Chinese society, but also hinder the overall comprehensive strength of the country, resulting in the decline of the overall strength of the country and the inability to gain the right to speak in the world system. Therefore, relevant staff gradually began to pay attention to petroleum geological exploration work, actively introduced new concepts, and reformed the traditional concepts according to the actual situation of China's petroleum exploitation work, so as to make the concept of petroleum exploration work meet the national development needs.

At present, China has paid more and more attention to the study of petroleum geological exploration. During the research, the researchers analyzed various plate structures and geology of oil-bearing basins, such as oil-bearing basin dynamics, oil-bearing system, reservoir lateral prediction, natural gas geology and so on. Through the research, we can master the specific topographic features and relationships of different petroliferous basins in an all-round way, thus improving the overall quality and efficiency of geological exploration. In addition, China's information technology is now developing well, and most oil companies gradually apply information technology in the process of petroleum geological exploration, optimizing and innovating traditional oil exploitation concepts and technologies, and forming new exploration concepts and advanced technical guidance, which is an excellent opportunity for petroleum geological exploration. Therefore, the relevant staff must seize this opportunity to optimize the petroleum geological exploration work, so as to provide power support for the harmonious development of Chinese society.

\subsection{Improvement of scientific and technological level of geological exploration}

Due to the influence of market economy, oil companies, as China's energy industry, are facing increasingly fierce competition pressure. China's science and technology have developed vigorously in recent years, which has a certain impact on oil exploration. Most oil companies in China gradually use science and technology to innovate exploration work, and increase the proportion of investment in science and technology. The purpose is to independently develop first-class exploration technology, thereby improving the comprehensive strength of enterprises and enabling enterprises to gain certain competitive advantages in the market economy. Therefore, the scientific and technological work of geological exploration in China plays a great role in the process of oil exploitation, which can improve the quality and efficiency of exploration work, reduce the exploration cost of enterprises and maximize the economic benefits of enterprises.

\subsection{Research on realizing cooperation}

Talent team is one of the important factors that determine the development process of oil enterprises, and it is also the key to determine the quality and efficiency of geological survey in oil enterprises. As one of the 
important energy sources in China, in order to improve the overall output of oil enterprises, the national government has issued many policies, the purpose of which is to combine enterprises and institutions, strengthen the cooperation between enterprises and institutions, and enable enterprises and institutions to cooperate with each other to study exploration technology. Therefore, the cooperative research mode has been widely used in petroleum geological exploration. The cooperative research mode can not only improve the utilization rate of resources to a certain extent, but also improve the exploration technology and rationally allocate the exploration capacity of oil enterprises.

\section{Classification of petroleum exploration technology in China}

\subsection{Logging technology}

This technology mainly measures the physical parameters of petroleum geology, and measures the physical properties of rock formations, such as acoustic characteristics and electrochemical characteristics. Nowadays, the development of information technology in China is ideal. Under this background, various logging technologies of Chinese petroleum enterprises have been greatly improved, such as imaging technology, magnetic resonance, casing and so on. Imaging logging technology mainly uses imaging instruments to collect and transmit its data in the exploration process, so as to provide accurate values for oil exploitation, thus improving the quality and efficiency of oil exploitation in all directions. Imaging instruments can also effectively improve the exploration depth, greatly improve the sampling rate of oil resources and improve the accuracy and reliability of its data. In addition, due to the rapid development of information technology in China, the data processing capability of Chinese oil companies in applying logging technology has also been greatly improved, such as data acquisition, data processing and data analysis, which provides technical support for the development of logging technology industry.

\subsection{Drilling technology}

Drilling technology is not widely used in petroleum exploration, mainly because drilling technology has higher construction cost compared with other exploration technologies. Therefore, the relevant staff need to innovate the drilling technology and reform its technology on the basis of reducing the cost of oil exploration. Workers can optimize traditional drilling technology and use information technology to establish visual drilling technology, and can also study deep well drilling technology and special process drilling technology according to the characteristics of oil wells, so as to ensure the quality and efficiency of drilling technology and reduce the production cost of enterprises.

\section{Content of petroleum reservoir evaluation system}

\subsection{Comprehensive classification evaluation}

The comprehensive classification evaluation system is mainly to clarify some parameters in the reservoir, and make an in-depth study on the factors that may affect the quality and efficiency of the reservoir based on these parameters, and make a scientific and reasonable evaluation of the storage, so as to formulate corresponding solutions. Because of the difference of reservoir types, geological exploration workers will have different ways in the process of exploration. Only by doing a good job of reservoir evaluation and ensuring that the staff can fully understand the actual situation of underground reservoirs, can the risks in the process of oil exploration be reduced to a certain extent, and the safety production work can be done while ensuring the quality and efficiency. Attention should be paid to the need for staff to make clear the reservoir parameters when evaluating the reservoir, so as to ensure the scientific and effective results and provide data support for oil exploration and development.

\subsection{Underbalanced drilling}

This method is one of the most widely used methods in reservoir evaluation system of petroleum enterprises at present. It mainly evaluates reservoirs when drilling with corresponding detection tools and equipment, which can not only improve the quality and efficiency of reservoir evaluation work to a certain extent, but also reduce the evaluation cost and improve the economic benefits of petroleum enterprises. Scientific and rational use of underbalanced drilling technology by workers can keep the bottom hole under pressure for a long time, thus introducing the fluids in the formation into the well. The staff can analyze and collect all the information of oil reservoir and dynamically evaluate the reservoir when obtaining the specific data of oil production, so as to ensure the quality and efficiency of evaluation. Compared with other evaluation techniques, underbalanced drilling evaluation technique has lower cost and higher work efficiency. Professionals comprehensively collect data from all aspects of the reservoir, and make scientific and reasonable analysis based on the data, so as to ensure the scientificity and rationality of its mining work, make its data more reliable and professional, and avoid potential safety hazards in the later mining process, endangering the personal safety of workers.

\subsection{Comprehensive quantitative}

The geological environment of oil geological reservoir is special, which is easily affected by many factors, resulting in changes in geological environment, such as diagenetic characteristics, reservoir characteristics, sedimentary characteristics and so on. Therefore, the relevant staff need to comprehensively consider the corresponding factors when evaluating the reservoir, so as to effectively 
improve the quality and efficiency of reservoir evaluation. The comprehensive quantitative evaluation system of storage is to comprehensively evaluate it according to its storage characteristics, which can comprehensively control the oil quality of different oil reservoirs in different regions and different stages. This method mainly combines various evaluation methods, such as grey correlation method and fuzzy comprehensive evaluation. The staff can master the corresponding information in all directions, so as to ensure the quality and safety of oil exploitation in the later stage. Because there are many aspects involved in reservoir evaluation, when applying comprehensive quantitative evaluation method, relevant staff need to select corresponding evaluation methods according to different reservoir areas and characteristics, and determine the number of related rights and interests, so as to improve the scientificity and accuracy of evaluation results in an all-round way, and reasonably distinguish reservoir characteristics of different intervals and regions. When the related staff evaluate the reservoir, they also need to comprehensively evaluate the related rock strata, so as to comprehensively collect all the influencing factors, provide accurate and reliable information for the mining personnel, and comprehensively improve the safety in the process of oil exploitation.

\section{Conclusions}

To sum up, although China's science and technology are developing well, and the development of new energy is strong, as a basic resource, the demand for oil, whether it is the development of China's industrial industry or the daily life of the public, is only increasing. At present, the petroleum resources developed by China can no longer meet the needs of the market. Therefore, relevant staff must actively introduce advanced scientific mining technologies, conduct in-depth research on petroleum geological exploration, improve the utilization rate of resources, and give full play to the role of petroleum resources. At the same time, the relevant staff also need to improve the storage evaluation system, so as to ensure the scientific and reasonable mining work, improve the output of oil enterprises in all directions, and provide power for the harmonious development of Chinese society.

\section{References}

1. Wan Peng, Wang Xinyi. Analysis of petroleum geological exploration and reservoir evaluation methods[J]. China Petroleum and Chemical Standards and Quality, 2021, 41(02): 4-6.

2. Lin Ziwei. Analysis of petroleum geological exploration and reservoir evaluation methods $[\mathrm{J}]$. China Petroleum and Chemical Standards and Quality, 2020, 40(15): 7-8.

3. Ning Guolan. Innovating petroleum geological exploration and reservoir evaluation methods with information technology[J]. Information System Engineering, 2019(07): 156.

4. Wang Xuansu. Discussion on petroleum geological exploration and reservoir evaluation methods[J]. China Petroleum and Chemical Standards and Quality, 2019, 39(13): 3-4. 